\title{
AVALIAÇÃO DE ASPECTOS ERGONÔMICOS E DE USABILIDADE RELACIONADOS AO ASSENTO MÚLTIPLO: LONGARINA PARA ESPERA
}

Raimundo Lopes Diniz, Dr.

Programa de Pós-Graduação em Design (UFMA)

rl.diniz@ufma.br

Ricardson Borges Vieira, Mestrando

Núcleo de Ergonomia em Processos e Produtos (UFMA)

ricardsonbv@yahoo.com.br

Larissa Raquel Ferro Marques, Iniciação Científica

Núcleo de Ergonomia em Processos e Produtos (UFMA)

larahferro@gmail.com

Resumo: Este estudo teve como objetivo avaliar os aspectos ergonômicos e de usabilidade de um assento tipo longarina para salas de espera, baseado nas normas vigentes para mobiliário do tipo assentos múltiplos e a Norma Regulamentadora 17 (MTE, SIT, 2002). Para a realização da avaliação, elaborou-se uma estratégia envolvendo o método de Silva (2003) com adaptações, as quais foram realizadas as seguintes etapas: 1) levantamento técnico dimensional do assento múltiplo - tipo longarina por meio de uma trena de precisão; 2) observações diretas e indiretas em situação real de uso; 3) avaliação subjetiva com aplicação de questionário de validação Diagrama de Segmentos Corporais para o Mapeamento de Desconforto/dor (DSCMD) (CORLETT, 1995), e um protocolo de avaliação dos assentos (adaptado de CORLETT, 1995); 4) avaliação de conformidade (comparação do assento testado com a literatura disponível - ABNT NBR 16031:2012 e ABNT NBR 13962:2006). Participaram do estudo 12 voluntários, que possuíam extremidade antropométrica na faixa dos seguintes percentis: P5M (feminino) e P95H (masculino). Os dados obtidos foram tabulados e analisados, e os resultados indicaram que o assento possui problemas com relação à altura da superfície do assento e o espaço de apoio para a região lombar. Concluiu-se que, apesar dos problemas encontrados, o produto avaliado está em conformidade com relação às recomendações da literatura, atendendo aos principais parâmetros das normas.

Palavras-chave: aspectos ergonômicos, usabilidade, longarina ou assento.

Abstract: This study aimed to evaluate the ergonomics and usability aspects of a seat type stringer for waiting rooms, based on existing standards for furniture classified as multiple seats and Brazilian Regulatory Standard number 17 (MTE, SIT, 2002). To perform the evaluation, it was 
elaborated a strategy involving the knowledge of the Silva (2003) with adaptations, from which the following steps were taken: 1) dimensional technical survey of the multiple seat - rail type, made with a precision measuring tape ; 2) field observations in real-use context; 3) subjective assessment using Body Segments for Discomfort/pain Mapping Diagram (DSCMD) (CORLETT, 1995), and an evaluation protocol of seats (adapted from CORLETT, 1995); 4) conformity assessment (comparison of the tested seat with the available literature - NBR 16031: 2012 and NBR 13962: 2006). The study included 12 volunteers who had anthropometric end range among the following anthropometric percentiles: P5M (female) and $\mathrm{P95H}$ (male). The results indicated that the seat has problems regarding the height of the seat surface and won the support space for the lower back. It was concluded that, despite of the problems encountered, the evaluated product is in compliance with the literature recommendations, taking into account the main parameters of Standards and Regulations.

Keywords: ergonomics, usability, stringer or seatone.

\section{INTRODUÇÃO}

Pheasant (1997) argumenta que a abordagem ergonômica em relação ao projeto pode ser resumida como o princípio do próprio projeto centrado ao usuário, ou seja, se um objeto, um sistema ou um ambiente é projetado para o uso humano, então seu projeto deve se basear nas características físicas e mentais do seu usuário humano, assim, o objetivo é alcançar a melhor integração possível entre o produto e seus usuários, no contexto da tarefa (trabalho) que deve ser desempenhada.

Segundo Moraes (1994), a ergonomia traz para o processo de projeto um enfoque mais sistemático para a análise, a especificação e a avaliação dos requisitos de usabilidade. O projeto ergonômico segue um desenvolvimento sistêmico e sistemático que se inicia com a delimitação do problema, segue com o diagnóstico ergonômico a partir da análise da tarefa, continua com o projeto ergonômico de alternativas e termina com testes e avaliações ergonômicas. São as exigências e constrangimentos da tarefa que propiciam a concepção do sistema - a configuração do produto em termos das funções a serem desempenhadas pelo homem ou pela máquina.

Conforme COURY (1995) é cada vez maior o tempo que passamos sentados no dia-a-dia: vendo televisão, lendo, no carro ou ônibus e, principalmente, trabalhando. Assim, pode-se destacar a função da cadeira para um ambiente de sala de espera, onde o indivíduo pode passar horas sentado à espera de determinado fim ou apenas para passar um período de descanso. De acordo com a autora, a postura sentada poderia ser vantajosa em relação à postura de pé, porque cansa menos, exige menor gasto energético, alivia pernas etc. No entanto, ela sobrecarrega nosso corpo principalmente quando permanecemos sentados e em condições inadequadas.

Assim, de maneira geral a ergonomia é indispensável para o design de cadeiras (assentos), pois ela põe em prática os seus conhecimentos sobre o usuário/ser humano, a anatomia, a biomecânica, a fisiologia, a antropometria da postura sentada e um estudo detalhado sobre as tarefas a serem desempenhadas, de acordo com o que propõe o produto (assento). Desta forma, este trabalho apresenta os resultados 
de uma avaliação ergonômica do assento múltiplo - tipo longarina (assento conjugado em 2 a 3 lugares), visando um melhor entendimento a respeito da sua composição técnica (projeto de produto) e o seu enquadramento conforme as normas técnicas vigentes e os princípios ergonômicos de usabilidade buscando a melhoria das condições de uso pelo usuário em potencial. Usou-se para este fim, o método proposto por Silva (2003).

\section{MÉTODOS E TÉCNICAS}

A presente avaliação foi uma solicitação de uma avaliação ergonômica do produto por uma empresa de móveis planejados, evidenciando um teste de usabilidade, culminando com um parecer ergonômico (laudo) sobre o produto, considerando as normas vigentes para mobiliário do tipo assentos múltiplos e a Norma Regulamentadora 17 (MTE, SIT, 2002).

Considera-se a presente avaliação como de cunho descritivo, de caráter exploratório, pois visou obter informações sobre a realidade do assento múltiplo - tipo longarina, como um mobiliário em outros lugares que demandam uma situação de espera, bem como a possibilidade de implementação de melhorias. A abordagem descritiva envolve quatro aspectos: a descrição, o registro, a análise e a interpretação de fenômenos (Marconi \& Lakatos, 1996). O caráter exploratório tem por objetivo proporcionar maior familiaridade com o problema, com vistas a torná-lo mais explícito ou a construir hipóteses.

\subsection{Método de avaliação de assentos (SILVA, 2003)}

Para a realização da avaliação, elaborou-se uma estratégia envolvendo o conhecimento de Silva (2003), mais adequado para produtos já configurados, com adaptações, no qual avalia o uso de cadeiras (assentos a nível geral) conforme os aspectos antropométricos e biomecânicos (contemplados pelas normas e recomendações da literatura, no que diz respeito ao desconforto/dor durante a jornada de trabalho) e também, segundo os aspectos estético-simbólicos (preferência pelos modelos testados, definida com base em entrevistas e questionários) conforme percebidos pelos usuários antes e após os testes.

O método é constituído de observações (diretas e indiretas para detecção de problemas e registro postural), questionários que visam, além da avaliação de percepção, sondar níveis de desconforto/dor, demanda da cadeira (atributos considerados mais importantes pelos usuários), entrevista aberta (identificação da percepção do usuário quanto aos critérios importantes em uma cadeira de trabalho) e experimentos comparativos dos modelos de cadeiras em situação real de trabalho. A metodologia conta também com avaliações de preferência e rejeição espontânea antes e após o experimento, seguida de questionários que avaliam: a diferença da sensação de desconforto/dor entre final e início do turno (estruturado a partir de um mapa de regiões corporais adaptado de Corlett, 1995), questionário para avaliação da satisfação com a cadeira em teste (que mede a satisfação com relação aos critérios: conforto, segurança, adaptabilidade, praticidade, adequação ao trabalho e aparência), e questionário para avaliação do grau de importância dos critérios de avaliação de cadeiras.

Com base no método de Silva (2003), a avaliação da realidade do assento múltiplo - tipo longarina apresentou as seguintes fases: 1) levantamento técnico 
dimensional do assento múltiplo - tipo longarina por meio de uma trena de precisão; 2) observações diretas e indiretas (de maneira sistemática, partindo de parâmetros pré-estabelecidos: segurança, biomecânica, conforto, dimensionamento, antropometria, praticidade, adaptabilidade), em situação real de uso, por meio de anotações em caderneta de campo; 3) avaliação subjetiva: aplicação de questionário de validação Diagrama de Segmentos Corporais para o Mapeamento de Desconforto/dor (DSCMD) (CORLETT, 1995) e um Protocolo de avaliação dos assentos (adaptado de CORLETT, 1995); 4) Avaliação de conformidade (Comparação do assento testado com a literatura disponível - ABNT NBR 16031:2012 e ABNT NBR 13962:2006).

\subsubsection{Sujeitos participantes}

Para a coleta de dados a respeito da percepção de usuários sobre assentos múltiplos - tipo longarina, contou-se com a participação de voluntários, alunos universitários. Os voluntários foram selecionados de acordo com as seguintes variáveis: 1) Idade, 2) Sexo, 3) Profissão, 4) Tempo de atividade na universidade (tempo em que o voluntário usa assentos múltiplos), 5) Turno de atividade (matutino, vespertino e noturno), 6) Altura, 7) Peso e 8) Percentil antropométrico. Desta forma, escolheram-se sujeitos de percentis mínimos e máximos femininos e masculinos. Adotou-se como extremidade antropométrica a faixa dos seguintes percentis: P5M (feminino) e P95H (masculino). No total, participaram da pesquisa 12 (doze) sujeitos. Para a avaliação antropométrica, levando-se em consideração a tabela do fator Estatura de Panero \& Zelnik (2000), sendo o P5M com 152,4 cm, o P5H com 163,3 cm, o P95M com $172,5 \mathrm{~cm}$ e o $\mathrm{P} 95 \mathrm{H}$ com $185,7 \mathrm{~cm}$. Todos os participantes tiveram sua identidade preservada e foram informados a respeito do objetivo da pesquisa assinando um Termo de Consentimento Livre e Esclarecido.

\subsubsection{Estratégia para a avaliação}

Antes de se iniciarem os testes, cada sujeito foi informado sobre a importância da avaliação e da sua participação, sobre as especificidades da realização da pesquisa e instruções da aplicação dos métodos e técnicas, assinalando sobre um termo de consentimento no processo de avaliação.

Helander et al. (1987), afirmam que para testar, com um nível elevado de confiabilidade, o desconforto/dor em assentos, o uso dos mesmos deve ser de pelo menos por três horas. Dependendo do motivo da investigação do desconforto/dor, o intervalo das coletas pode variar quanto ao número de minutos, horas, dias, ou um tempo maior.

A coleta dos dados do desconforto/dor pode ser arquivada em folhas separadas por tempo de coleta, permitindo, ou não, que o trabalhador compare com seus dados coletados anteriormente (STRAKER, 1999). O período entre a sensação de desconforto/dor do usuário/trabalhador e a coleta destes dados é importante para a avaliação do desconforto/dor (STRAKER, 1999). Branton (1966) sugeriu, devido a experiências anteriores com resultados de desconforto/dor baseados na memória do trabalhador, que as informações sejam coletadas enquanto o trabalhador está vivenciando o desconforto/dor, em situação real.

Desta forma, cada sujeito voluntário utilizou a amostra do assento múltiplo durante um intervalo de tempo pré-estipulado (três horas), simulando o uso de uma sala de espera (Helander et al., 1987). Em seguida, cada um respondeu a um 
questionário de validação, descrevendo seus dados pessoais (nome, profissão, idade, sexo, altura, peso, ano de ingresso) e sua experiência/percepção quanto aos fatores Conforto, Praticidade, Segurança, Adaptabilidade, Beleza/aparência (estética) e o que gostaria que o assento tivesse quanto a melhorias.

As principais posturas foram observadas sistematicamente, elaborando-se um comparativo do quadro postural entre os percentis extremos. Aplicou-se, também uma técnica de avaliação de desconforto/dor, denominada Diagrama de Segmentos Corporais (CORLETT, 1995), e em seguida um protocolo de avaliação dos assentos.

O protocolo de avaliação de assentos continha questões relativas à satisfação do usuário quanto ao assento, envolvendo itens: assento, encosto e apoio para os braços. Para a aferição do nível de satisfação utilizou-se uma escala de duas âncoras (pouco/muito) e uma âncora no centro (médio ou neutro), com 8 (oito) centímetros de tamanho, sendo que, e ao longo desta os sujeitos (respondentes) marcaram a sua percepção sobre cada item do assento em termos de níveis de satisfação. Levou-se em conta a percepção do usuário quanto a itens: conforto, segurança, adequação, dimensionamento e funcionalidade (figura 1 ).

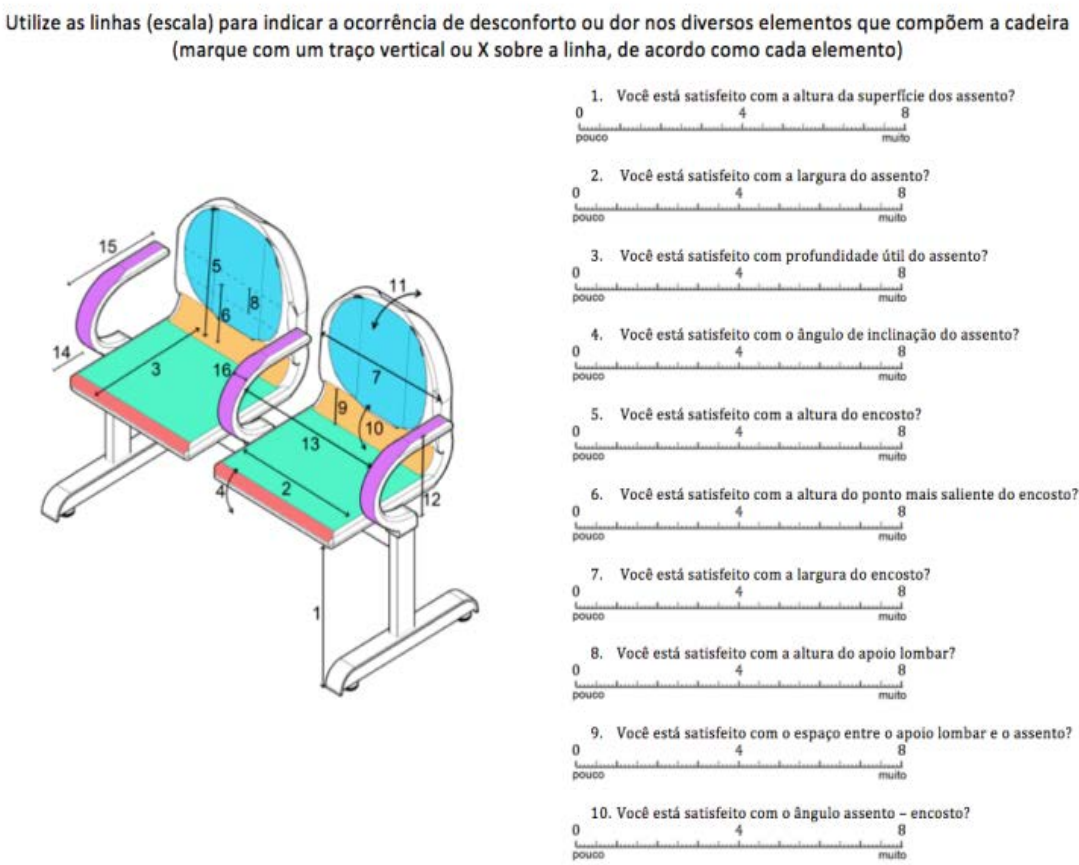

Figura 1 - Protocolo de avaliação dos assentos.

Fonte: adaptado de Corlett, 1995.

Para a ponderação tanto do protocolo quanto dos questionários, o peso de cada item foi gerado por sua média aritmética. Os dados foram tabulados em planilha Excel, gerando-se gráficos representativos dos resultados encontrados.

Simultaneamente à avaliação subjetiva (percepção dos sujeitos participantes dos testes), houve o levantamento técnico dimensional do assento múltiplo tipo longarina por meio de uma trena de precisão e gabarito de carga (ABNT NBR 13962:2006) e, ainda, a confrontação dos resultados com as Normas Brasileiras relativas a esse mobiliário (ABNT NBR 16031:2012; ABNT NBR 13962:2006), com a Norma Regulamentadora 17 (MTE, SIT, 2002) e, também, com a literatura técnico-científica disponível. 


\section{RESULTADOS E DISCUSSÕES}

\subsection{Sujeitos}

A média de idade dos participantes foi de 20,67 anos (Desvio padrão: 2,38 anos), variando entre 18 e 25 anos, todos estudantes universitários, de diferentes turnos e atividades, com média de tempo de 2 anos e 4 meses como estudantes; média do fator peso de 67,69 Kg (Desvio padrão: 67,79 kg (variando de 48 a 85kg), sendo 8 destros e 4 canhotos.

\subsection{Perfil dimensional e técnico}

O assento avaliado, do tipo LONGARINA 02 (DOIS) LUGARES, possuía estrutura interna em aço e percinta elástica totalmente revestida em poliuretano flexível, acabamento superficial em pintura eletrostática totalmente automatizada em epóxi pó, assento revestido totalmente em couro ecológico, apoio de braços individual em chapa de aço curvado, totalmente injetado em poliuretano texturizado (figura 02).
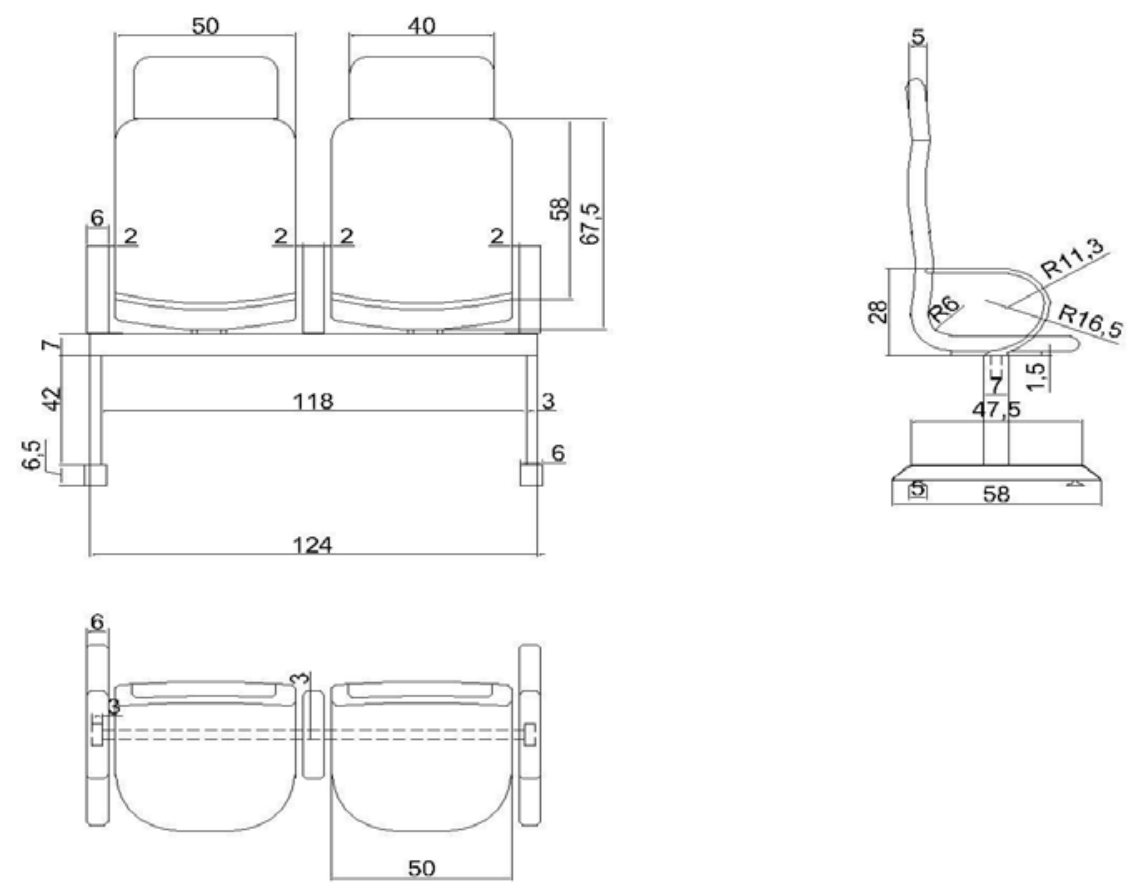

Figura 02 - Vista Ortogonal Frontal, superior e lateral. Dimensionamentos principais (em milímetros) do assento múltiplo do tipo longarina elaborado pelos autores.

Fonte: Elaborado pelos autores, com base na pesquisa realizada.

\subsection{Avaliação subjetiva}

3.3.1 Avaliação de níveis de desconforto/dor: diagrama de segmentos corporais (CORLETT, 1995)

Observa-se que os resultados apontaram pouco nível de desconforto/dor para a maioria dos segmentos. Para os respondentes, observou-se pouco desconforto/dor no ombro $(1,9)$, pé $(1,8)$, braço $(1,6)$ e coxa $(1,4)$, respectivamente, para o lado esquerdo do corpo (figura 3 ). 


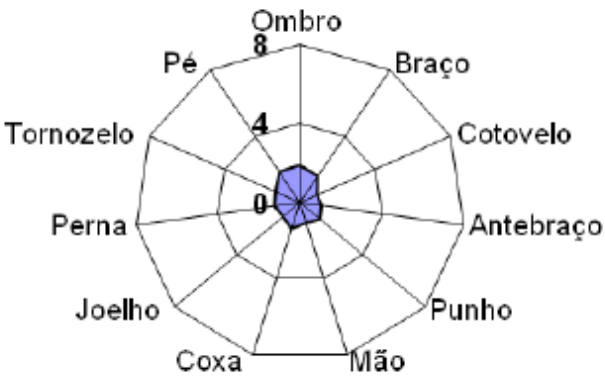

Figura 03 - Resultados da avaliação do nível de desconforto/dor para o lado esquerdo.

Os resultados da avaliação do nível de desconforto/dor, para o lado direito, foram similares aos resultados para o lado esquerdo (figura 4). Para os respondentes, observa-se pouco desconforto no pé $(1,8)$, coxa $(1,6)$, ombro $(1,4)$ e perna $(1,4)$, respectivamente. Assim, caracterizando-se como nível reduzido de desconforto/dor.

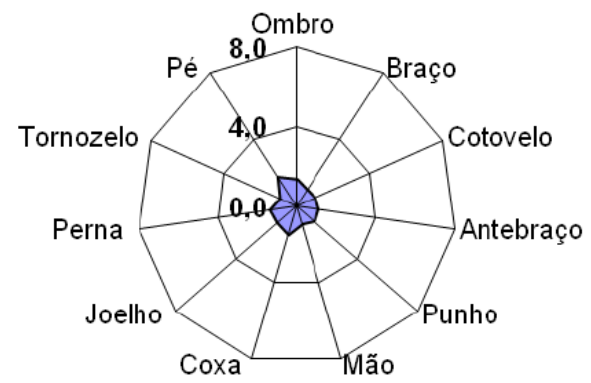

Figura 04 - Resultados da avaliação do nível de desconforto/dor para o lado direito.

Para o segmento corporal tronco, os resultados da avaliação do nível de desconforto/dor apresentaram-se reduzidos (figura 5). No geral, apontaram pouco desconforto/dor na região superior da costa $(3,3)$, pescoço $(2,6)$, ombro $(1,4)$ e perna $(1,4)$, respectivamente.

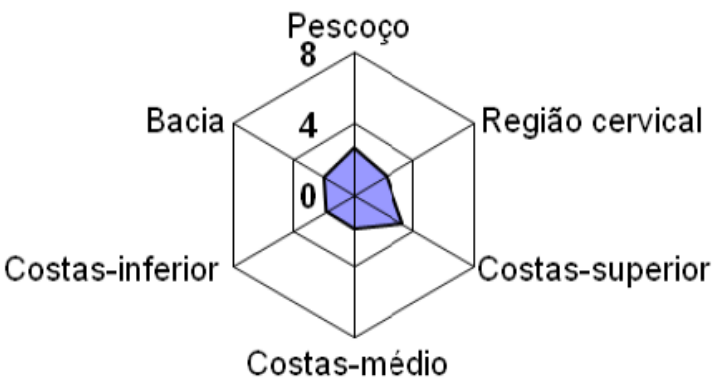

Figura 05 - Resultados da avaliação do nível de desconforto/dor para o segmento tronco.

\subsubsection{Protocolo de avaliação dos assentos (adaptado de Corlett, 1995).}

Os resultados do protocolo de avaliação de assentos estão apresentados na figura 06. 


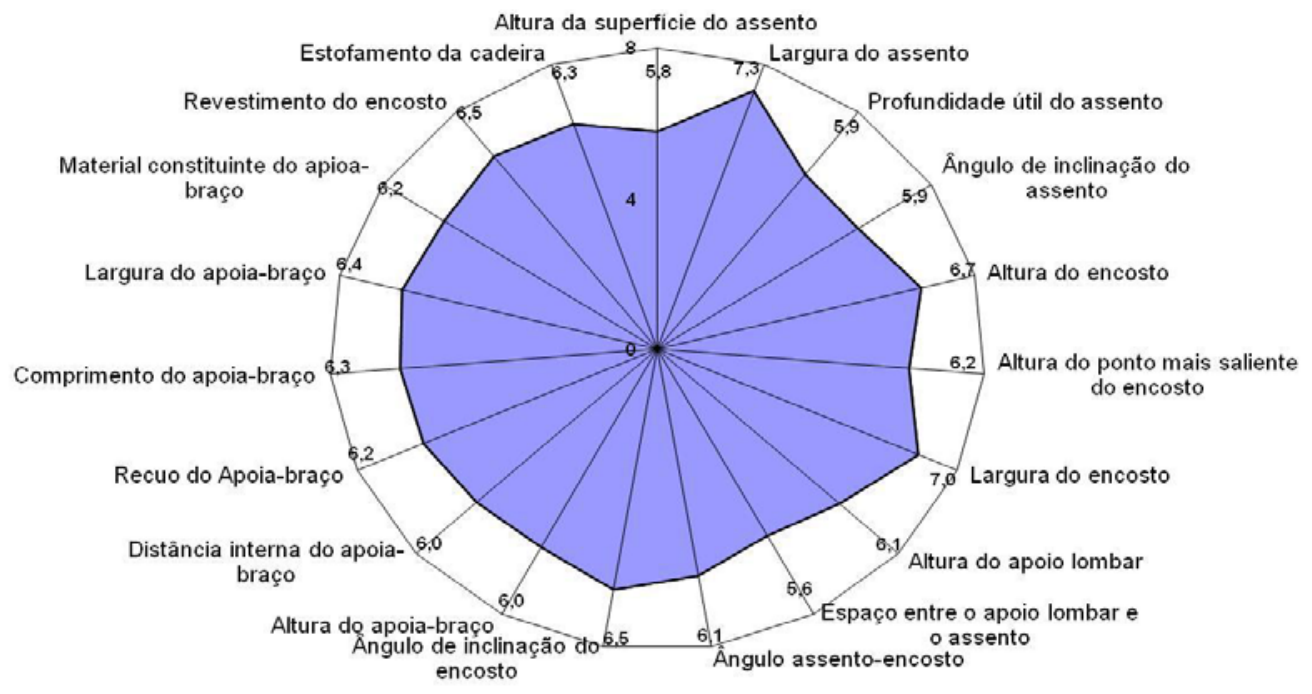

Figura 06 - Resultados da avaliação do nível de desconforto/dor para o segmento tronco.

Estes resultados apontam que em relação à satisfação do usuário quanto ao assento avaliado, os sujeitos apontaram elevados níveis de satisfação, com respostas próximas ao nível "muito" satisfeito. Destacaram-se os itens: largura do assento $(7,3)$; largura do encosto $(7,0)$, altura do encosto $(6,7)$ e largura do apoia braços $(6,4)$.

Em uma análise geral pode-se verificar que os sujeitos, após o uso simulado do assento, mostraram-se satisfeitos com o assento avaliado.

\subsubsection{Questionário para avaliação do conforto}

Os resultados da avaliação do conforto são apresentados na figura 07.

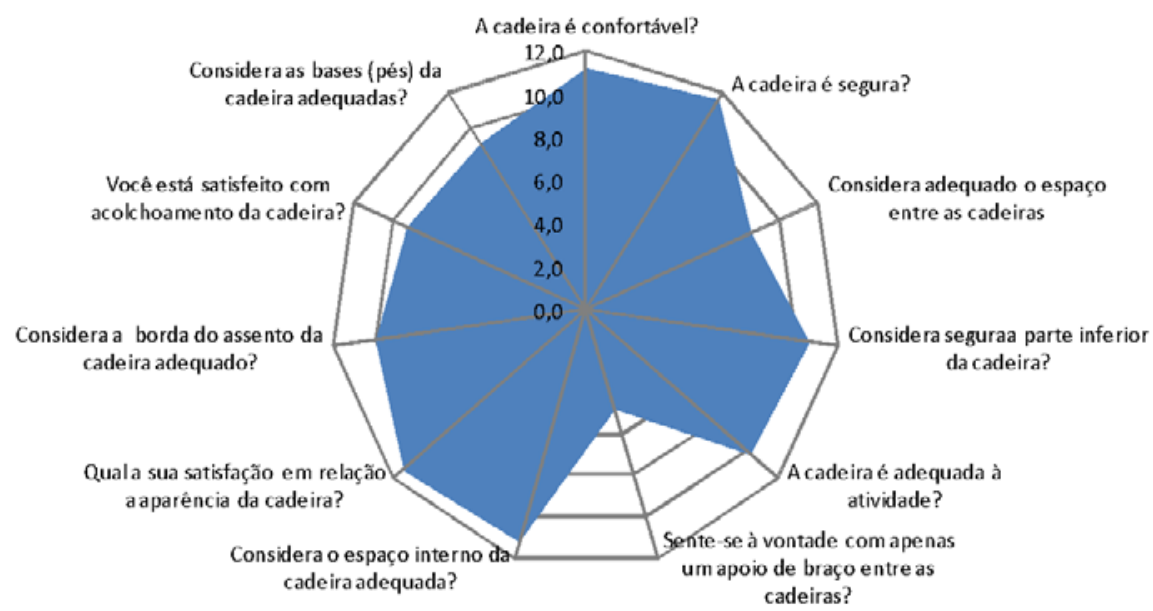

Figura 07 - Resultados da avaliação do conforto.

A avaliação subjetiva do conforto apontou que os sujeitos avaliaram o assento como confortável. Além disso, consideraram o assento seguro, adequado à atividade, com espaço interno adequado, de aparência satisfatória e com borda adequada. Apenas a existência de um único apoio de braço entre as cadeiras não se mostrou plenamente satisfatório. 


\subsection{Quadro postural comparativo entre os percentis extremos}

Os resultados comparativos da análise realizada entre os percentis, através de observações sistemáticas com registro em caderneta de campo estão apresentados na tabela 1.

Tabela 1 - Tabela postural comparativa entre os percentis extremos

\begin{tabular}{ll}
\hline VARIÁVEL & ANÁLISE \\
\hline Altura do assento & $\begin{array}{l}\text { Assento alto para o P05M. Fornece pressão na área inferior das coxas, } \\
\text { caracterizando-se como inadequado para suportar o peso do corpo, com } \\
\text { elevado risco de dores na região inferior das pernas, joelhos e pés. }\end{array}$ \\
\hline Largura do assento & Largura do assento/encosto adequado para ambos os percentis. \\
\hline Apoio para braços & Apoio para braços adequado para ambos os percentis. \\
\hline Fonte: Elaborado pelos autores, com base na pesquisa realizada.
\end{tabular}

\subsection{Avaliação de conformidade}

3.5.1. Comparação do assento testado com a literatura disponível: ABNT NBR 16031:2012 e ABNT NBR 13962:2006

A ABNT (Associação Brasileira de Normas Técnicas) de acordo com a NBR 13960:1997 que trata de móveis para escritório, diz que as cadeiras estão classificadas de acordo com a sua utilização ou aplicação mais característica. De acordo com o item 4.2.1 que trata de cadeira de espera ou cadeira de diálogo, cujas características físicas estão apresentadas nas classes 4.1.1, 4.1.1.1; 4.1.2, 4.1.2.1 e 4.1.3. Pode-se observar na tabela tabela 2 .

Tabela 2 - Comparação do assento testado com a ABNT NBR 16031:2012 e ABNT NBR 13962:2006

\begin{tabular}{|c|c|c|c|}
\hline \multirow[b]{2}{*}{ ABNT NBR 16031:2012/ NBR 13962:2006 } & \multicolumn{2}{|c|}{ NORMA } & \multirow[b]{2}{*}{$\begin{array}{l}\text { ASSENTO AVALIADO } \\
(\mathrm{cm})\end{array}$} \\
\hline & $\begin{array}{l}\text { MíNI } \\
\text { MO } \\
(\mathrm{cm})\end{array}$ & $\begin{array}{l}\text { MÁXI } \\
\text { MO } \\
(\mathrm{cm})\end{array}$ & \\
\hline Altura da superfície do assento & 42 & 50 & 50,2 (recomenda-se 43) \\
\hline Largura do assento & 40 & - & 50 \\
\hline Profundidade da superfície do assento & 38 & - & 41,8 \\
\hline Profundidade útil do assento & 38 & 44 & 36 \\
\hline Distância entre a borda do assento e o eixo de rotação & 27 & - & (não se aplica) \\
\hline Ângulo de inclinação do assento & $0^{\circ}$ & $-7^{\circ}$ & $0^{\circ}$ \\
\hline Altura do encosto & 24 & - & 62,8 \\
\hline Altura do ponto mais saliente do encosto & 17 & 22 & 21 (recomenda-se 17) \\
\hline Altura da borda superior do encosto & 36 & - & 82,8 \\
\hline Altura do apóia-braço & 20 & 25 & 21,5 \\
\hline Recuo do apóia-braço & 10 & - & 10,4 \\
\hline Distância interna entre os apóia-braços & 46 & - & 54 \\
\hline Comprimento do apóia-braço & 20 & - & 33 \\
\hline Largura do apóia-braço & 4 & - & 6 \\
\hline Largura do encosto & 30,5 & - & 50 \\
\hline Raio de curvatura do encosto & 40 & - & 70,5 \\
\hline Ângulo de inclinação do encosto & $0^{\circ}$ & $15^{\circ}$ & $0^{\circ}$ \\
\hline Altura do apoio lombar & 10 & - & 12 \\
\hline Espaço entre apoio lombar e assento & 13 & 19 & 11 (recomenda-se 13) \\
\hline Ângulo assento-encosto & $90^{\circ}$ & $105^{\circ}$ & $90^{\circ}$ \\
\hline Profundidade do apoio lombar & 1,3 & 2,5 & 4,3 \\
\hline
\end{tabular}


O assento avaliado não se enquadrou nos seguintes itens: altura da superfície do assento, altura do ponto mais saliente do encosto, largura do encosto e espaço entre o apoio lombar e assento (tabela 2).

\subsubsection{NR17 (MTE, SIT, 2002) e literatura disponível (SILVA, 2003; PANERO e ZELNIK, 1993; COURY, 1995).}

De acordo com a Norma Regulamentadora $\mathrm{n}$ 17 $\mathrm{O}$ assento deve ser adequado à natureza da tarefa e às dimensões antropométricas. Da população a conformação do assento deve também permite alteração de postura aliviando assim as pressões sobre os discos intervertebrais e as tensões sobre os músculos dorsais de sustentação, portanto assentos anatômicos em que as nádegas se encaixam neles não são recomendados, pois permitem poucos movimentos. A densidade do assento também é importante para suporta às tuberosidades isquiáticas. É preferível um assento com inclinação para trás em torno de $5^{\circ}$ com relação ao horizontal. Isso impede que a pessoa escorregue para frente, o que pode acontecer em assentos paralelos ao solo.

Em relação a NR17, item 17.3 denominado Mobiliário dos postos de trabalho, o assento em questão se enquadra no "item c", pois possui características dimensionais que possibilitam posicionamento e movimentação adequados dos segmentos corporais, atendendo aos requisitos mínimos de conforto (altura compatível com os usuários e à natureza da sua funcionalidade - para espera; pouca ou nenhuma conformação na base do assento; borda frontal arredondada; encosto com forma levemente adaptada ao corpo para proteção da região lombar).

Ainda em relação a NR17, o assento avaliado não requer apoio de pés, visto que a sua proposta funcional não é para execução de atividades em tempo prolongado e, sim, para ser utilizado em sala de recepção/espera e não para ser utilizado em um posto de trabalho.

Em relação à literatura disponível a tabela 3 apresenta os principais resultados.

Tabela 3 - Avaliação do assento quanto à literatura disponível

\begin{tabular}{ll}
\hline PARÂMETRO & $\begin{array}{l}\text { AVALIAÇÃO DE } \\
\text { CONFORMIDADE }\end{array}$ \\
\hline $\begin{array}{l}\text { O assento deve ter área suficiente para abranger o centro de gravidade e precisa } \\
\text { fornecer base suficiente para equilíbrio sem, no entanto, impedir que as pessoas } \\
\text { mantenham a perna em posição confortável (com joelhos flexionados e pés } \\
\text { apoiados); }\end{array}$ & OK \\
\hline $\begin{array}{l}\text { O assento não deve machucar o tecido posterior da coxa e as tuberosidades } \\
\text { isquiáticas; }\end{array}$ & OK \\
\hline $\begin{array}{l}\text { A altura do encosto do assento deve permitir regulagem em função das diferenças } \\
\text { antropométricas; é importante que o encosto forneça um bom suporte lombar. }\end{array}$ & OK \\
\hline $\begin{array}{l}\text { A amostra do assento deve fornecer manual do usuário, no qual constem a } \\
\text { classificação, as instruções para uso e as recomendações de segurança cabíveis; }\end{array}$ & Navaliado disponível/Não \\
\hline $\begin{array}{l}\text { As bordas do assento, do encosto, do apoia-braço, dos manípulos de regulagem e } \\
\text { dos demais elementos construtivos da cadeira que sejam acessíveis ao usuário } \\
\begin{array}{l}\text { quando em posição sentada devem ser arredondadas, com raio de curvatura } \\
\text { maior que } 2 \text { mm. }\end{array}\end{array}$ & OK \\
\hline $\begin{array}{l}\text { As partes lubrificadas da cadeira devem estar protegidas, de modo a evitar o } \\
\text { contato com o corpo e com as roupas do usuário em posição sentada. }\end{array}$ & OK \\
\hline
\end{tabular}

Fonte: Elaborado pelo autor, com base na pesquisa realizada. 
Os resultados da avaliação de conformidade apresentam que o assento avaliado se encontra em conformidade com a maioria dos itens analisados, devendose observar as recomendações indicadas.

\section{CONSIDERAÇÕES FINAIS}

Na presente análise propôs-se avaliar os aspectos ergonômicos e de usabilidade relacionados ao assento múltiplo para espera de uma Empresa, modelo LONGARINA de 02 (dois) e 03 (três) lugares, considerando os requisitos de Segurança, Conforto, Praticidade, Adaptabilidade, dimensionamento e Beleza (estética) e enfocando os fatores técnicos da Ergonomia.

Quanto ao dimensionamento do assento a maioria das dimensões da cadeira está em conformidade com a norma, entretanto, as recomendações quanto à altura do assento devem ser rigorosamente consideradas. As recomendações quanto às outras dimensões em desconformidade também devem ser priorizadas. A avaliação dos níveis de desconforto/dor mostrou-se satisfatória, já que os níveis de desconforto apontados foram baixos, próximos ao "0", ou seja, nenhum desconforto/dor.

Quanto aos requisitos de conforto, segurança e aparência, a cadeira foi considerada pelos sujeitos como segura, adequada à atividade, com espaço interno adequado, de aparência satisfatória e com borda adequada. Quanto à conformidade com relação às recomendações da literatura, o assento avaliado atende aos principais parâmetros.

\section{AGRADECIMENTOS}

Livia Flávia, André Demaison, Denilson Santos, Samuel Silva, Mycon dos Anjos, Paula Maia, Rubenio Barros.

\section{REFERÊNCIAS}

ASSOCIAÇÃO BRASILEIRA DE NORMAS TÉCNICAS. NBR 13962. Móveis para Escritório Cadeiras - Características Físicas e Dimensionais. Rio de Janeiro, 1997.

ASSOCIAÇÃO BRASILEIRA DE NORMAS TÉCNICAS. NBR 14110. Móveis para Escritório Cadeiras - Ensaios de estabilidade, resistência e durabilidade. Rio de Janeiro, 1998.

CHAPANIS, Alphonse. Ergonomics in product development: a personalized review. Proceedings of IEA 94. IEA, Toronto. 1994. Vol 1. Pp. $52-54$.

CORLETT, E. Nigel. The evaluation of posture and its effects. In: WILSON, John R. CORLETT, E. Nigel. Evaluation of human work - A practical ergonomics methodology. Taylor \& Francis: Londres, 1995. Pp. $663-713$.

FOGLIATTO, F. S., GUIMARÃES, L. B. Design Macroergonômico: uma proposta metodológica para projeto de produto. In: Guimarães, L. B. (Ed.), Revista Produto \& Produção. PPGEP/UFRGS: Porto Alegre, 1999. Vol. 3, n. 3, pp. 1- 15.

HELANDER, M. G.; CZAJA, S.J.; DRURY, C. G.; CARY, J. M.; BURRI, G. An Ergonomic Evaluation of Office Chairs. Office: Technology and People, v. 3, p. 247-262,1987.

HIGNETT, S., McATAMNEY, L. Rapid Entire Body Assessment (REBA). Applied

Ergonomics. Elsevier Science Ltd. № 31, 2000. pp. $201-205$. 
INTERNATIONAL ERGONOMICS ASSOCIATION (IEA). The discipline of ergonomics. Texto recuperado da internet no dia 14/10/2003. http://www.iea.cc/ergonomics/. 2003.

MARCONI, Marina de Andrade; LAKATOS, Eva Maria. Técnicas de Pesquisa: Planejamento e execução de pesquisas, amostragens e técnicas de pesquisa; elaboração, análise e interpretação de dados. São Paulo: Editora Atlas, 1996, 3 ed., 231p.

MORAES, Anamaria de. Ergonomia e conflito homem $x$ máquina: carga de trabalho e custos humanos do trabalho; penosidade física, psíquica e cognitiva. In: MORAES, Anamaria de; VELLOSO, Francisco. J. L. Informatização, automação: sistemas, produtos e programas. Anais do 20 Encontro Carioca de Ergonomia, Rio de Janeiro, Clube de Engenharia - RJ, 1994. Pp. 3 - 14.

MORAES, Anamaria de. MONT'ALVÃO, Claudia. Ergonomia: conceitos e aplicações. Rio de Janeiro: 2AB, 1998. $120 \mathrm{p}$.

MINISTÉRIO DO TRABALHO E EMPREGO. Normas Regulamentadoras de Segurança e Saúde do Trabalho: NR 17 Ergonomia. Disponível em:

http://www.mte.gov.br/Temas/SegSau/Legislacao/Normas/conteudo/nr17/default.as p. Acessado em: 14/01/2002.

NEESE CONSULTING COMPANY. Rapid Entire Body Assessment (REBA) software ${ }^{\circledR}$. Versão 1.3. 2001.

PANERO, J.; ZELNIK, M. Las Dimensiones Humanas en los Espacios Interiores: Estándares Antropométricos. México: G. Gili, 2000.

PHEASANT, Steven. Bodyspace. Anthropometry, ergonomics and the design of work. London: Taylor \& Francis, 1997.

SILVA, E. (2003). Avaliação da preferência de cadeiras para diferentes tipos de trabalhos de escritório. Dissertação de Mestrado. Universidade Federal do Rio Grande do Sul. Escola de Engenharia. Programa de Pós-Graduação em Engenharia de Produção. Porto Alegre: PPGEP-UFRGS. 245p.

SOARES, Marcelo Márcio (2001). Contribuições da ergonomia do produto ao design e avaliação de mobiliários escolares: carteira universitária; um estudo de caso. In: MORAES, A., FRISONI, B. (Eds.). ERGODESIGN - PRODUTOS E PROCESSOS. Rio de janeiro: 2AB - Série Design. Pp. 141-168. 